\title{
The role of Cardiac Magnetic Resonance (CMR) in the diagnosis of cardiomyopathy: A systematic review
}

\section{Henry Anselmo Mayala, Khamis Hassan Bakari, Wang Zhaohui}

Wuhan Union Hospital, Tongji Medical College of Huazhong, University of Science and Technology, China
Date Received: 28-Aug-2017

Revision Received: 01-Nov-2017

Date Accepted: 31-Jan-2018

Correspondence: Wang Zhaohui

ttps://dx.doi.org/10.4314/mmj.v31i3.14

\section{Background}

Abstract

Myocardial pathologies are significant causes of morbidity and mortality in patients worldwide. Ischemic and non-ischemic cardiomyopathies have become a worldwide epidemic of the 21 st century with an increasing impact on health care systems. The 2012 European Society of Cardiology and 2013 American College of Cardiology Foundation/American Heart Association guidelines provide current therapy guidance to reduce mortality and morbidity.

Methods

This was a systematic review involving cardiac magnetic resonance (CMR) studies for the diagnosis of cardiomyopathy from January 2013 to April 2017. Out of 62 reviewed studies, only 12 were included in our study.

Results

The average sensitivity and specificity of CMR in the diagnosis of cardiomyopathy was $86.75 \%(95 \%$ confidence interval [CI], $70.30 \%$ to $92.58 \%$ ) and $81.75 \%(95 \%$ CI, $73.0 \%$ to $87.6 \%$ ), respectively, and the positive predictive and negative predictive values were $80.17 \%$ and $86.75 \%$, respectively.

Conclusion

Despite some limitations, our study shows that CMR has high sensitivity, specificity, and positive predictive value in diagnosing different types of cardiomyopathy. CMR may be used to differentiate types of cardiomyopathy, accurately quantify the chamber dimensions, volumes, and cardiac function, which make it useful for prognosis as well.

Keywords: Cardiac magnetic resonance, dilated cardiomyopathy, hypertrophic cardiomyopathy, ischemic cardiomyopathy, late gadolinium enhancement

\section{Introduction}

Myocardial pathologies are significant causes of morbidity and mortality in patients worldwide. Ischemic and nonischemic cardiomyopathies have become a worldwide epidemic of the 21 st century with an increasing impact on health care systems. The 2012 European Society of Cardiology and 2013 American College of Cardiology Foundation/American Heart Association guidelines provide current therapy guidance to reduce mortality and morbidity ${ }^{1,2,3,4}$. The revascularization of coronary arteries in acute myocardial infarction has become the treatment of choice, and revascularization procedures have evolved significantly. Coronary angiography is invasive and provides information only on the anatomical status of obstructive coronary lesions. Several non-invasive methods have been developed to aid in the assessment of the functional state of the myocardium, namely contraction and perfusion, as well as microvascular and cellular integrity, including positron emission tomography and contrast, enhanced echocardiography ${ }^{5,6,7,8}$. More recently, the development of delayed contrast-enhanced magnetic resonance imaging (DE-MRI) has served a purpose as another imaging tool. In ischemic cardiomyopathy, the sub-endocardium is always enhanced on DE-MRI, while a patchy mid-myocardial enhancement is observed in dilated cardiomyopathy (DCM). Furthermore, patients with restrictive cardiomyopathy showed delayed myocardial improvement over the entire sub-endocardial circumference $\mathrm{e}^{9,10,11,12}$.

Heart failure represents the final stage in the continuum of cardiovascular diseases. Cardiac remodelling is a key component of heart failure that progresses from adaptive to maladaptive as the disorder worsens. Increased myocardial wall stress during diastole contributes to the development and progression of adverse cardiac remodeling ${ }^{13,14,15}$.

Cardiac magnetic resonance is superior to other cardiac imaging modalities such as echocardiography, computed tomography angiography and coronary angiography in determining the type of cardiomyopathy, and cardiac function $^{16,17}$.

\section{Methods}

\section{Patient characteristics}

The age of participants in the included 12 cardiomyopathy studies ranged from 18 to 87 years, with dilated cardiomyopathy being a more seen pathology in the studies followed by ischemic cardiomyopathy. The patient characteristics are summarized in Table 1.

\section{Identification of studies and journals}

We identified published studies using CMR in the diagnosis of different types of cardiomyopathy in original and review articles by systematic searches of PubMed, MedLine, Cochrane database and Embase, and by manual searches of listed references in the papers, we found. We limited our search to studies published from January 2013 to April 2017 because, during this period, we noted an increase in the application of CMR in diagnosing different types of cardiomyopathy. The keywords used were: "dilated cardiomyopathy", "ischemic cardiomyopathy", "hypertrophic cardiomyopathy", 
Table 1: Characteristics of patients

\begin{tabular}{l|l}
\hline $\begin{array}{l}\text { Category } \\
\text { Sample size information }\end{array}$ & \\
\hline Total number of patients included & 999 \\
\hline Number of studies reporting on sample size & 12 \\
\hline Range of sample size reported & $23-150$ \\
\hline Age of participants & \\
\hline Number of studies reporting on age & 10 \\
\hline Age range, yrs & $18-87$ \\
\hline Type of cardiomyopathy & \\
\hline Ischemic cardiomyopathy & 193 \\
\hline Dilated cardiomyopathy & 337 \\
\hline Dual pathologies (NICM and DCM) & 16 \\
\hline Hypertrophic cardiomyopathy & 70 \\
\hline Tachycardia-induced cardiomyopathy & 55 \\
\hline Myocarditis & 138 \\
\hline Cardiac amyloidosis & 119 \\
\hline Cardiac sarcoidosis & 14 \\
\hline Left ventricle non-compaction & 57 \\
\hline Other tests & \\
\hline Histopathology & 1 \\
\hline Echocardiography & 2 \\
\hline Coronary angiography & 1
\end{tabular}

Abbreviations: $\mathrm{NICM}=$ nonischemic cardiomyopathy, DCM= dilated cardiomyopathy

"myocarditis", "cardiac amyloidosis", "cardiac sarcoidosis", and "cardiac MR", or "LGE CMR" (late gadolinium enhancement cardiovascular magnetic resonance), "Cine CMR", and "sensitivity" or "specificity". We identified 62 studies through this search strategy. We further screened the reference list of the retrieved studies for any additional publications. There were no restrictions on studies based on their sample size.

\section{Eligibility criteria}

We considered all eligible studies that evaluated the role of CMR in the diagnosis of cardiomyopathy. We also included studies with sufficient information to allow the calculation of sensitivity and specificity. We excluded meeting reports, abstracts, and reviews whose final stories were unavailable.

\section{Data extraction}

For each eligible study, we extracted the following information: author names, journal, year of publication, number of enrolled patients, the age of study patients, study design, and CMR protocol.

\section{Statistical analysis}

Statistical analysis was done using MedCalc for Windows version 64 bits; we calculated the sensitivity, specificity, positive predictive value, negative predictive value, positive likely-hood ratio, and negative likelihood ratio.

\section{Results}

\section{Eligible studies}

The search yielded 35 relevant studies. Of these, due to limited data, 23 studies were excluded, and 12 studies were available for systematic review. Figure 1 summarizes the flow

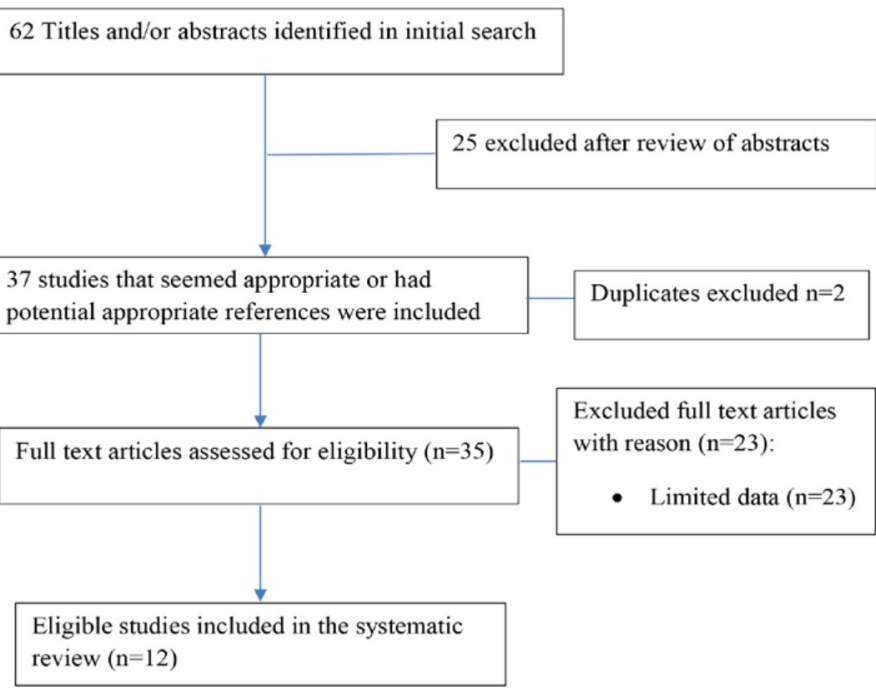

Figure 1: The flow diagram of study selection process for systematic review

Table 2: Individual studies with sample sizes and types of cardiomyopathy

\begin{tabular}{|c|c|c|c|}
\hline Study & $\begin{array}{l}\text { S a mple } \\
\text { size }\end{array}$ & CMR & Findings \\
\hline $\begin{array}{l}\text { Goebel et al. }{ }^{18} \\
2016\end{array}$ & 150 & $\begin{array}{l}\text { T1 mapping } \\
\text { CMR }\end{array}$ & $\begin{array}{l}\text { Does not differentiate healthy } \\
\text { and diffusely diseased } \\
\text { myocardium }\end{array}$ \\
\hline $\begin{array}{l}\text { Makoto et al. }{ }^{19} \\
2016\end{array}$ & 44 & LGE CMR & $\begin{array}{l}\text { LE in CS predominantly } \\
\text { basal, mid septum and } \\
\text { throughout the LV, while in } \\
\text { DCM, LE was localized in the } \\
\text { basal and mid septum } \\
\end{array}$ \\
\hline $\begin{array}{l}\text { Mikami et al. }{ }^{20} \\
2016\end{array}$ & 118 & LGE CMR & Septal fibrosis \\
\hline $\begin{array}{l}\text { Okada et al. }{ }^{21} \\
2016\end{array}$ & 102 & LGE CMR & $\begin{array}{l}\text { TIC had a significant lower } \\
\text { RVEF, and a larger RVEDV } \\
\text { and RVEDS }\end{array}$ \\
\hline $\begin{array}{l}\text { Kwong et al.22 } \\
2015\end{array}$ & 81 & $\begin{array}{l}\text { Cine SSFP } \\
\text { and LGE }\end{array}$ & \begin{tabular}{|lrr} 
CA mean proportion \\
of atrial enhancement \\
was significantly greater \\
compared to SH and NIDCM
\end{tabular} \\
\hline $\begin{array}{ll}\text { Maurizio } & \text { et } \\
\text { al. }^{23} 2015 & \end{array}$ & 77 & LGE CMR & \begin{tabular}{|ll}
$\begin{array}{l}\text { Hypertrophied } \\
\text { indicating regional } \\
\text { in } \mathrm{HCM}\end{array}$ & $\begin{array}{l}\text { septum } \\
\text { fibrosis }\end{array}$ \\
\end{tabular} \\
\hline $\begin{array}{ll}\text { Schwab } & \text { et } \\
\text { al. }{ }^{24} 2015 & \\
\end{array}$ & 43 & CMR & Wall motion abnormalities \\
\hline $\begin{array}{ll}\begin{array}{l}\text { Nguyen } \\
\text { al. }{ }^{25} 2015\end{array} & \text { et } \\
\end{array}$ & 23 & $\begin{array}{l}\text { C M R / L G E } \\
\text { CMR }\end{array}$ & Diffuse myocardial fibrosis \\
\hline $\begin{array}{l}\text { Dungu et al. }{ }^{26} \\
2013\end{array}$ & 97 & LGE CMR & $\begin{array}{l}\text { Distinguished ATTR from AL } \\
\text { cardiac amyloidosis }\end{array}$ \\
\hline $\begin{array}{l}\text { Ferreira et } \\
\text { al. }^{27} 2013\end{array}$ & 50 & $\begin{array}{l}\text { T1 mapping } \\
\text { CMR }\end{array}$ & $\begin{array}{l}\text { T1 mapping is a criterion } \\
\text { for detection of acute } \\
\text { myocarditis with a higher } \\
\text { sensitivity }\end{array}$ \\
\hline $\begin{array}{l}\text { Choi et al. }{ }^{28} \\
2016\end{array}$ & 114 & $\begin{array}{l}\text { Cine CMR/ } \\
\text { LGE CMR }\end{array}$ & $\begin{array}{l}\text { Classification of distribution } \\
\text { of trabeculation, } 43.9 \% \\
\text { global type, } 56.2 \% \text { apical } \\
\text { type }\end{array}$ \\
\hline $\begin{array}{l}\text { Gulsin et al. }{ }^{29} \\
2017\end{array}$ & 100 & \begin{tabular}{|l} 
C in e C M R / \\
LGE CMR
\end{tabular} & Global LV hypokinesis \\
\hline
\end{tabular}

Abbreviations: $\mathrm{CMR}=$ cardiac magnetic resonance, $\mathrm{LGE}=$ late gadolinium enhancement, $\mathrm{LE}=$ late enhancement, $\mathrm{CS}=$ cardiac sarcoidosis, $\mathrm{DCM}=$ dilated cardiomyopathy, $\mathrm{TIC}=$ tachycardia induced cardiomyopathy, RVEDV $=$ right ventricle end diastolic volume, RVEDS= right ventricle end systolic volume, $\mathrm{CA}=$ cardiac amyloidosis, $\mathrm{SH}=$ systemic hypertension, NIDCM= Nonischemic dilated cardiomyopathy, $\mathrm{HCM}=$ hypertrophic cardiomyopathy, AL= amyloid light chain, ATTR= transthyretin related Amyloidosis, SSFP $=$ steady state free precision 
diagram of how eligible studies were obtained. These studies were selected because they related to our analysis, they were recent, and they had likely extractable data as shown in figure 1.

Table 3: Showing individual studies with sensitivity, specificity and confidence intervals

\begin{tabular}{|c|c|c|c|c|c|}
\hline Study & Sensitivity & $95 \% \mathrm{Cl}$ & Specificity & $95 \% \mathrm{Cl}$ & FPR(1-TPR) \\
\hline $\begin{array}{l}\text { Goebel et al. }{ }^{18} \\
2016\end{array}$ & 0.85 & $0.75-0.91$ & 0.75 & $0.66-0.83$ & 0.15 \\
\hline $\begin{array}{l}\text { Makoto et al. }{ }^{19} \\
2016\end{array}$ & 0.68 & $0.57-0.78$ & 0.63 & $0.53-0.72$ & 0.32 \\
\hline $\begin{array}{l}\text { Mikami et al. }{ }^{20} \\
2016\end{array}$ & 0.70 & $0.60-0.79$ & 0.71 & $0.61-0.80$ & 0.30 \\
\hline $\begin{array}{l}\text { Okada et al. }{ }^{21} \\
2016\end{array}$ & 0.88 & $0.79-0.95$ & 0.75 & $0.66-0.82$ & 0.12 \\
\hline $\begin{array}{l}\text { Kwong et al. }{ }^{22} \\
2015\end{array}$ & 0.93 & $0.85-0.97$ & 0.80 & $0.71-0.87$ & 0.07 \\
\hline $\begin{array}{l}\text { Maurizio et al. }{ }^{23} \\
2015\end{array}$ & 0.99 & $0.93-1.00$ & 0.83 & $0.75-0.89$ & 0.01 \\
\hline $\begin{array}{l}\text { Schwab et al. }{ }^{24} \\
2015\end{array}$ & 0.86 & $0.72-0.95$ & 1.0 & $0.90-1.0$ & 0.14 \\
\hline $\begin{array}{l}\text { Nguyen et al. }{ }^{25} \\
2015\end{array}$ & 0.84 & $0.75-0.95$ & 0.80 & $0.72-0.88$ & 0.16 \\
\hline $\begin{array}{l}\text { Dungu et al. }{ }^{26} \\
2013\end{array}$ & 0.96 & $0.89-0.99$ & 0.88 & $0.80-0.93$ & 0.04 \\
\hline $\begin{array}{l}\text { Ferreira et al. }{ }^{27} \\
2013\end{array}$ & 0.91 & $0.83-0.96$ & 0.90 & $0.82-0.95$ & 0.09 \\
\hline $\begin{array}{l}\text { Choi et al. }{ }^{28} \\
2016\end{array}$ & 0.85 & $0.76-0.92$ & 0.76 & \begin{tabular}{|c|}
$0.64-0.83$ \\
\end{tabular} & 0.15 \\
\hline $\begin{array}{l}\text { Gulsin et al. }{ }^{29} \\
2017\end{array}$ & 0.96 & $0.90-0.99$ & 1.00 & $0.96-1.0$ & 0.04 \\
\hline
\end{tabular}

Abbreviations: $\mathrm{Cl}=$ confidence interval, $\mathrm{FPR}=$ false positive rate, $\mathrm{TPR}=$ true positive rate

Table 4: Showing individual studies with positive predictive value and negative predictive value

\begin{tabular}{l|l|l|}
\hline $\begin{array}{l}\text { Study } \\
\text { Goebel et al. }{ }^{18} 2016\end{array}$ & PPV & NPV \\
\hline Makoto et al. ${ }^{19} 2016$ & 0.71 & 0.87 \\
\hline Mikami et al. ${ }^{20} 2016$ & 0.72 & 0.73 \\
\hline Okada et al. ${ }^{21} 2016$ & 0.69 & 0.69 \\
\hline Kwong et al. ${ }^{22} 2015$ & 0.76 & 0.91 \\
\hline Maurizio et al. ${ }^{23} 2015$ & 0.80 & 0.94 \\
\hline Schwab et al. ${ }^{24} 2015$ & 1.00 & 0.99 \\
\hline Nguyen et al. ${ }^{25} 2015$ & 0.81 & 0.85 \\
\hline Dungu et al. ${ }^{26} 2013$ & 0.87 & 0.96 \\
\hline Ferreira et al. ${ }^{27} 2013$ & 0.97 & 0.90 \\
\hline Choi et al..${ }^{28} 2016$ & 0.72 & 0.88 \\
\hline Gulsin et al. ${ }^{29} 2017$ & 1.00 & 0.96
\end{tabular}

Abbreviations: $\mathrm{PPV}=$ positive predictive value, $\mathrm{NPV}=$ negative predictive value

\section{Study description and patient characteristics}

The 12 studies had a total of 999 patients. The sample size of the studies ranged from 23 to 150. The age range of the study subjects, 18 to 87 years, was reported in 10 reviews. Dilated cardiomyopathy was more prevalent in the studies, followed by ischemic cardiomyopathy and the least pervasive was cardiac sarcoidosis. The average sensitivity and specificity of CMR in the diagnosis of cardiomyopathy was $86.75 \%$ (95\% confidence interval [CI], $70.30 \%$ to $92.58 \%$ ) and $81.75 \%$ (95\% CI, $73.0 \%$ to $87.6 \%$ ), respectively. The positive predictive and negative predictive values were $80.17 \%$ and $86.75 \%$. Tables $1,2,3$, and 4 summarize the results.

\section{Discussion}

Cardiomyopathy has been diagnosed and assessed by echocardiogram or cardiac computed tomography for many years. With technological advancements and further research, several studies have addressed the role of cardiac magnetic resonance $(\mathrm{CMR})$ as a functional modality in the diagnosis and quantification of cardiac function in different types of cardiomyopathy. CMR can measure and quantify chamber sizes and left ventricle (LV) systolic function accurately. Therefore, Cardiac Magnetic Resonance has potential as a tool to assess patient prognosis.

In our systematic review of 12 studies, we found moderately high sensitivity and specificity values for CMR, which implies that CMR is a standard valuable imaging modality for diagnosing different types of cardiomyopathy. Goebel et al. could differentiate between dilated cardiomyopathy, hypertrophic cardiomyopathy (HCM), and healthy heart function through left ventricle quantification; patients with dilated cardiomyopathy had higher left ventricle enddiastolic volume, end-systolic volume, and systolic volume and significantly lower ejection fractions compared to patients with healthy hearts ${ }^{18}$. Hypertrophic cardiomyopathy patients had substantially higher end-diastolic septum thickness compared to healthy subjects ${ }^{18}$. This reinforces the importance of cardiac magnetic resonance in diagnosing cardiomyopathy. CMR can also be useful in differentiating ischemic and non-ischemic cardiomyopathy, which might facilitate optimal management of patients.

According to this study, we appreciate the ability of CMR to diagnose and differentiate types of cardiomyopathies, through its high spatial resolution and tomographic image capabilities. Late gadolinium magnetic resonance was able to distinguish cardiac sarcoidosis and dilated cardiomyopathy ${ }^{19}$. Furthermore, Late Gadolinium Enhancement cardiac magnetic resonance was also used to diagnose non-ischemic Dilated cardiomyopathy by revealing septal fibrosis and other studies identified a mid-wall septal striae pattern of Late gadolinium enhancement to be the most reliable predictor of future events ${ }^{20}$. Moreover, Cardiac magnetic resonance was also used to assess the diagnostic value of early right ventricular dysfunction to predict tachycardiainduced cardiomyopathy, in which the studies revealed that CMR imaging assessing right ventricular function might be valuable compared with echocardiography ${ }^{21}$.

Ischemic cardiomyopathy can easily be missed in routine screening of suspected coronary heart disease patients particularly in microvascular coronary artery disease whereby coronary angiogram may be the standard investigation expected to be done. But with the current new technology of Positron emission magnetic resonance imaging (PETMRI), it will be easy to know which areas are poorly perfused and confirmed by measuring coronary flow reserve ${ }^{30}$. Among other non-invasive imaging modalities, CMR is emerging as a highly sensitive and specific test for myocardial ischemia and infarction. Resting perfusion in CMR is used to evaluate microvascular obstruction, which is shown to predict adverse left ventricular remodelling ${ }^{31}$. Thus, as previous studies have indicated, the significance of magnetic resonance in diagnosing different types of cardiomyopathies especially in differentiating ischemic versus nonischemic cardiomyopathy, we concur with our results of MRI having high sensitivity and specificity. 


\section{Clinical implications}

CMR is superior in evaluating cardiac function, LV dimensions, and capable of differentiating types of cardiomyopathies with a specificity of $81.75 \%$ and sensitivity of $86.75 \%$. In the clinical setting, the ability to diagnose the form of cardiomyopathy helps in choosing the specific treatment. In a study of Choi et al. ${ }^{28}$ they used cardiac magnetic resonance imaging to establish refined diagnostic criteria for left ventricle non-compaction. As a quantitative approach, we have shown that a trabeculated left ventricle volume of $>35 \%$ of the $\mathrm{LV}$ myocardial volume is diagnostic for left ventricle non-compaction with high specificity. Our study has also shown the diagnostic accuracy of late gadolinium-enhanced cardiac magnetic resonance for establishing the etiology of heart failure. Late gadolinium enhancement-cardiac magnetic resonance (LGE-CMR) was able to differentiate between ischemic cardiomyopathy and non-ischemic cardiomyopathy. Furthermore, the addition of adenosine stress perfusion-cardiac magnetic resonance (SPCMR) to cine and LGE-CMR provided minimal incremental diagnostic yield for determining the etiology of heart failure in patients with severe left ventricle systolic dysfunction ${ }^{29}$.

\section{Limitations}

The inclusion of studies with small sample sizes may influence the statistical power of the individual research and lead to imprecise and inconclusive results. Other limitations include bias through selection, publication, and verification of the studies.

\section{Conclusion}

Despite some limitations, our study shows that cardiac magnetic resonance (CMR) has high sensitivity, specificity, and positive predictive value in diagnosing different types of cardiomyopathy. CMR may be used to differentiate types of cardiomyopathy, accurately quantify the chamber dimensions, volumes, and cardiac function which make it useful for prognosis as well.

\section{Disclosure}

The authors declare no conflict of interest.

\section{References}

1. Bui AL, Horwich TB, Fonarow GC. Epidemiology and risk profile of heart failure. Nat. Rev. Cardiol. 2011; 8(1): 30-41. doi: 10.1038/ nrcardio.2010.165

2. Saeed M, Hetts SW, ablonowski R, Wilson MW. Magnetic resonance imaging and multi-detector computed tomography assessment of extracellular compartment in ischemic and non-ischemic myocardial pathologies. World J Cardiol. 2014; 6(11): 1192-1208.doi: 10.4330/ wjc.v6.i11.1192

3. Ziaeian B, Fonarow GC. Epidemiology and etiology of heart failure, Nat. Rev. Cardiol. 2016;13(6): 368-378. doi: 10.1038/nrcardio.2016.25

4. Mayala HA, Mayala M, Mutta R, Bakari KH, Hui WZ. The Effect of interleukin-6, microRNA-21 and the role of atorvastatin in dilated cardiomyopathy- A review of literature. EJBPS, 2017; 4(9):103-106.

5. Foussas SG, Tsiaousis GZ. Revascularization treatment in patients with coronary artery disease. Hippokratia. 2008;12(1):3-10.

6. Kim H-Y, Choi J-H. How to utilize coronary computed tomography angiography in the treatment of coronary artery disease. J Cardiovasc Ultrasound, 2015; 23(4): 204-208. doi: 10.4250/jcu.2015.23.4.204

7. Shah T, Geleris JD, Zhong M, Swaminathan RV, Kim LK, Feldman DN. Fractional flow reserve to guide surgical coronary revascularization. J Thorac Dis 2017; 9(Suppl 4): S317-S326. doi: 10.21037/jtd.2017.03.55

8. Arbab-Zadeh A. Stress testing and non-invasive coronary angiography in patients with suspected coronary artery disease: time for a new paradigm. Int Heart J 2012; 7(1): e2. doi: 10.4081/hi.2012.e2

9. Vermes E, Carbone I, Friedricha MG, Merchant N. Patterns of myocardial late enhancement: Typical and atypical features. Arch Cardiovasc Dis 105:300-308. doi:10.1016/j.acvd.2011.12.006

10. Doltra A, Amundsen BH, Gebker R, Fleck E, Kelle S.Emerging concepts for myocardial late gadolinium enhancement MRI. Curr Cardiol Rev. 2013;9(3):185-90.: 185-190. doi: 10.2174/1573403X113099990030

11. Satoh H, Sano M, Suwa K, Saitoh T, Nobuhara M, Saotome M, et al. Distribution of late gadolinium enhancement in various types of cardiomyopathies: Significance in the differential diagnosis, clinical features, and prognosis. World J Cardiol. 2014; 6(7): 585-601. doi: $10.4330 /$ wjc.v6.i7.585

12. Franco A, Javidi S, Ruehm SG. Delayed myocardial enhancement in cardiac magnetic resonance imaging. J Radiol Case Rep. 2015; 9(6): 6-18. doi: 10.3941 /jrcr.v9i6.2328

13. Yip GW, Fung JWH, Tan Y-T, Sanderson JE. Hypertension and heart failure: a dysfunction of systole, diastole or both? J Hum Hypertens 2009:23, 295-306; doi:10.1038/jhh.2008.141

14. Burchfield JS , Xie M, Hill JA. Pathological Ventricular Remodeling: Mechanisms: Part 1 of 2. Circ. 2013; 128(4): 388-400.doi: 10.1161/ CIRCULATIONAHA.113.001878

15. Eriksson J, Bolger AF, Ebbers T, Carlhäll CJ. Assessment of left ventricular hemodynamic forces in healthy subjects and patients with dilated cardiomyopathy using 4D flow MRI. Physiol. Rep 2016; 4(3): pii: e12685.. doi: 10.14814/phy2.12685

16. Assunção FB, de Oliveira DCL, Souza VF, M Nacif MS. Cardiac magnetic resonance and computed tomography in ischemic cardiomyopathy: An update. Radiol Bras.2016; 49(1): 26-34, doi: 10.1590/0100-3984.2014.0055

17. Berman DS, Hachamovitch R, Shaw LJ, Friedman JD, Hayes SW, Thomson LE, et al. Roles of nuclear cardiology, cardiac computed tomography, and cardiac magnetic resonance: Assessment of patients with suspected coronary artery disease. J Nucl Med. 2006; 47:74-82.

18. Goebel J, Seifert I, Nensa F, Schemuth HP, Maderwald S, Quick $\mathrm{HH}$, et al. 2016. Can native T1 mapping differentiate between healthy and diffuse diseased myocardium in clinical routine cardiac MR imaging? PLoS ONE 11(5): e0155591. https://doi.org/10.1371/journal. pone. 0155591

19. Sano M, Satoh H, Suwa K, Saotome M, Urushida T, Katoh H, et al. Intra-cardiac distribution of late gadolinium enhancement in cardiac sarcoidosis and dilated cardiomyopathy. World J Cardiol. 2016; 8(9): 496-503. doi: 10.4330/wjc.v8.i9.496

20. Mikami Y, Cornhill A, Heydari B, Joncas SX, Almehmadi F, Zahrani $\mathrm{M}$, et al. Objective criteria for septal fibrosis in non-ischemic dilated cardiomyopathy: validated for the prediction of future cardiovascular events. J Cardiovasc Magn Reson 2016; 18:82, doi:10.1186/s12968016-0300-z

21. Okada A, Nakajima I, Morita Y, Inoue YY, Kamakura T, Wada M, et al. Diagnostic value of right ventricular dysfunction in tachycardiainduced cardiomyopathy using cardiac magnetic resonance imaging, Circ. J 2016;80:2141-2148, doi:10.1253/circj. CJ-16-0532

22. Kwong R, Sara P, Sharmila D. Multimodality imaging in the assessment of myocardial viability. Heart Fail Rev. 2011; 16(4): 381395. doi: 10.1007/s10741-010-9201-7

23. Maurizio G, Nuno C, Antonello D'A, Oliver B, Bernard C, Laurent $\mathrm{D}$, et al. The multi-modality cardiac imaging approach to the Athlete's heart: an expert consensus of the European Association of Cardiovascular Imaging. Eur Heart J Cardiovasc Imaging. 2015; 16:353 doi:10.1093/ehjci/jeu323 
24. Schwab J, Rogg HJ, Pauschinger M, Fessele K, Bareiter T, Bär I, et al. Functional and Morphological Parameters with Tissue Characterization of Cardiovascular Magnetic Imaging in Clinically Verified "Infarct-like Myocarditis”. Rofo. 2016;188(4):365-73. doi: 10.1055/s-0041-108200.

25. Nguyen C, Minjie L, Zhaoyang F, Xiaoming B, Peter K, Shihua $\mathrm{Z}$, et al. Contrast-free detection of myocardial fibrosis in hypertrophic cardiomyopathy patients with diffusion-weighted cardiovascular magnetic resonance. Journal of Cardiovascular Magnetic Resonance201517:107, https://doi.org/10.1186/s12968-015-0214-1

26. Dungu JN, Oswaldo V, Jennifer H., Simon D. J. G, Dorota R, Janet A. G, et al. CMR-Based Differentiation of AL and ATTR Cardiac Amyloidosis. 2014; Jacc: cardiovascular imaging vol. 7, issue 2, DOI: 10.1016/j.jcmg.2013.08.015

27. Ferreira VM, Piechnik SK, Dall'Armellina E, Karamitsos TD, Francis JM, Ntusi N, et al. T(1) mapping for the diagnosis of acute myocarditis using CMR: comparison to T2-weighted and late gadolinium enhanced imaging. JACC Cardiovasc Imaging. 2013;6(10):1048-1058. doi: 10.1016/j.jcmg.2013.03.008.
28. Choi Y, Kim SM, Lee S-C, Chang S, Jang SY, Choe YH. Quantification of left ventricular trabeculae using cardiovascular magnetic resonance for the diagnosis of left ventricular non-compaction: evaluation of trabecular volume and refined semi-quantitative criteria. J Cardiovasc Magn Reson 2016; 18:24, doi:10.1186/s12968-016-0245-2

29. Gulsin GS, Shetye A, Khoo J, Swarbrick DJ, Levelt E, Lai FY, et al. Does stress perfusion imaging improve the diagnostic accuracy of late gadolinium-enhanced cardiac magnetic resonance for establishing the etiology of heart failure? BMC Cardiovasc Dis 2017; 17:98. doi:10.1186/s12872-017-0529-y

30. Heo R, Nakazato R, Kalra D, Min JK. Noninvasive imaging in coronary artery disease. Semin Nucl Med. 2014;44(5):398-409, doi:10.1053/semnuclmed.2014.05.004

31. Hamirani YS, Kramer CM. Cardiac MRI assessment of myocardial perfusion. Future Cardiol. 2014;10(3):349-358, doi: 10.2217/fca.14.18 